\title{
Bags for life: The embedding of ethical consumerism
}

Article type: Manuscript for consideration under "sustainability"

Running head: Embedding ethical consumerism

Title: Bags for life: The embedding of ethical consumerism

Corresponding author:

Dr Pamela Yeow

Kent Business School

University of Kent

Parkwood Road

Canterbury

Kent CT2 7PE

T: +44 (0)1227 823991

E: p.m.yeow@kent.ac.uk

Dr Alison Dean

Kent Business School

University of Kent

Parkwood Road

Canterbury

Kent CT2 7PE

T: +44 (0)1227 824051

E: a.dean@kent.ac.uk

Dr Danielle Tucker

Health Management Group

Imperial College Business School

Tanaka Building

South Kensington Campus

London SW7 2AZ

T: +44 (0)20 75949059

E: danielle.tucker@imperial.ac.uk

\section{Citing this article:}

This document represents an accepted draft of the final manuscript. For the published version of this paper please see: http://link.springer.com/article/10.1007\%2Fs10551-013-1900-2

This paper should be cited as follows:

Yeow, P. M.; Dean, A.; and Tucker, D. A. (2014) 'Bags for Life’: Embedding ethical consumerism. Journal of Business Ethics. 125(1): 87-99 


\begin{abstract}
The aim of this paper is to understand why some ethical behaviours fail to embed, and importantly what can be done about it. We address this by looking at an example where ethical behaviour has not become the norm, i.e. the widespread, habitual, use of 'bags for life'. This is an interesting case because whilst a consistent message of 'saving the environment' has been the basis of the promotion of 'bags for life' in the United Kingdom for many years, their uptake has only recently become more widespread and still remains at low levels. Through an exploratory study, we unpack some of the contextual barriers which may influence ethical consumerism. We do this by examining the attitudes which influenced people to start using 'bags for life', and how people persuade others to use 'bags for life'. We use a case study analysis to try and understand why ethical behaviour change has stalled and not become sustained. We find that both individuals and institutions play a significant interaction role in encouraging a sustained behavioural change towards ethical consumerism.
\end{abstract}

Key words: Attitude-intention-behaviour gap, embedding behaviour change, environment plastic bags, ethical consumerism

\begin{abstract}
Abbreviations
$\mathrm{BBC}-$ British Broadcasting Corporation.

BRC - British Retail Consortium, a leading trade association in the United Kingdom (UK) representing all forms of retailers.
\end{abstract}

DEFRA - Department for Environment, Food and Rural Affairs, a UK government department responsible for policy and regulations on the environment, food and rural affairs.

WRAP - WRAP is funded by all four governments across the UK and the EU and run programmes in England, Scotland, Wales and Northern Ireland to help people recycle more and waste less, both at home and at work.

Figures

Figure 1: Number of bags issued compared with proportion of bags issued

Figure 2: 'Bags for Life' Timeline ( $\mathrm{t}=0$, Spring 2010) 


\section{$\underline{\text { Introduction }}$}

While ethical consumerism has existed for centuries, it is only within the last three decades that it has moved from a niche concern to a mainstream phenomenon (Low and Davenport, 2007) attracting growing academic interest across a range of disciplines from psychology through sociology and anthropology to business (Newholm and Shaw, 2007, p.253; Papaoikonomou et al., 2012). According to DEFRA (2007, cited in Haddock-Fraser, 2010), “62\% of adults claim to have become more environmentally active in recent years". In the past decade consumers' attitudes towards ethical issues have become of increasing relevance to businesses, so much so that they are now considered a key aspect of business strategy (British Retail Consortium (BRC), 2010). Consumers and businesses alike are beginning to realise the importance of customer values and how meeting demands is critical if they wish to gain competitive advantage. According to Bray et al. (2011) and Cooper-Martin and Holbrook (1993) the definition of ethical consumer behaviour is "decision-making, purchases and other consumption experiences that are affected by the consumer's ethical concerns." Reduction in packaging and excess material is one area where ethical consumerism and business ethics meet.

The aim of this paper is to understand why some ethical behaviours fail to embed, and importantly what can be done about it. We address this by looking at the example of the ownership and usage of 'bags for life'. 'Bag for life' is the common term in the United Kingdom (UK) to describe a reusable shopping bag, a type of bag that is intentionally designed to be reused several times. These are seen to be the alternative to single use plastic or paper bags. This is an interesting case because whilst a consistent message of 'saving the environment' has been the basis of the promotion of 'bags for life' in the UK for many years, their uptake has only recently become more widespread, and in terms of total bags provided, still remains at low levels.

Single-use plastic bags have become ubiquitous and the environmental impact of their disposal is well documented (Sharp et al., 2010). James and Grant (2003) and Lewis, Verghese and Fitzpatrick (2010) found that polymer-based 'bags for life' have lower environmental impacts than all types of singleuse bags. Furthermore, they point out that degradable single-use bags have similar greenhouse and 
water pollution effects to traditional single-use (non-degradable) bags. Litter impact was found to be lowest for the 'bags for life' too.

In 2005, WRAP commissioned a study into consumer use of and attitudes towards free single-use plastic bags and 'bags for life' (Andrew Irving Associates, 2005). It was found that whereas threequarters of their sample were aware of 'bags for life', only one-third had ever purchased a 'bag for life'. Of those, only one-third used their bag every time they went shopping. A large minority of these 'bags for life' purchasers said that they used theirs very occasionally. Significantly, re-usage of 'bags for life' occurred only if and when respondents remembered to do so. Barriers to re-usage also included the reluctance to use another store's 'bag for life' when shopping in any given store, not wanting to appear 'cheap', and an unwillingness to put non-food items into a bag previously used for food shopping, particularly where contamination could occur.

A variety of initiatives to reduce the impact of plastic bags on the environment have been introduced around the world, ranging from outright bans at community, regional and national level by government, through government imposed taxes and retailer levied charges to voluntary action by retailers, manufacturers and consumers (Roach, 2008; BBC News, 2008). In the UK in January 2007, it was reported in a British broadsheet that Marks and Spencer had launched an environmental strategy which included ending the distribution of free single-use carrier bags. In 2008, the BRC and seven of Britain's then major supermarket chains agreed with the UK Governments to reduce the number of single-use carrier bags provided to customers by $50 \%$ by Spring 2009 compared with 2006 levels (WRAP, 2010). We refer to this as 'the voluntary agreement' throughout this paper. Results in July 2009 showed that a 48\% reduction had been achieved since 2006 (WRAP, 2010). However, results for subsequent years following the end of the voluntary agreement - 2010 and 2011 showed the number of single-use bags provided had risen again year-on-year by $5 \%$ and $5.4 \%$ respectively (WRAP, 2012). Research by Hayabuchi, et al. (2005) examining retail outlets that had instigated their own voluntary programmes to encourage consumers to reuse plastic bags, suggests that without legislative enforcement, a reduction in the use of single-use plastic bags by more than $50 \%$ is unlikely. Although 'bags for life' were introduced as an alternative to single-use bags, the proportion 
of single-use bags as percentage of total bags issued has remained roughly stable at $95 \%$ since 2009 and that of 'bags for life' at 5\% (WRAP, 2012). This would suggest that the use of 'bags for life' in the period 2009 -2012 had not become sufficiently embedded and integrated behaviour (May and Finch, 2009) to lead to a continued substitution of 'bags for life' for single-use bags at the point of issue (see figure 1).

INSERT FIGURE 1 ABOUT HERE (Figure 1: Number of bags issued compared with proportion of bags issued)

Increasing social concern about the environment is reflected in the growth in consumers' interest in ethical consumption (Newholm and Shaw, 2007; The Co-operative Group, 2012). Despite this, authors (Auger and Devinney, 2007; Bray et al., 2011; Carrigan and Attala, 2001; Carrington et al., 2010; Chatzidakis et al., 2007; Cowe and Williams, 2000; d'Astous and Legendre, 2009; Papaoikonomou et al., 2012) point to an attitude-behaviour gap where although people may express a positive attitude toward being ethical or socially responsible in their consumption, they do not always act on that attitude.

This paper uses a variety of case study data and participant surveys to consider whether a switch to 'bags for life' has embedded since the report on carrier bag usage to WRAP in 2005 (Andrew Irving Associates, 2005). Our findings show that an attitude-behaviour gap still exists in the UK and is not being reduced. We investigate the role of context, specifically the role of supermarkets/retailers, as a pivotal reinforcing mechanism in achieving enduring behaviour change.

\section{Attitude-behaviour gap}

While numbers of studies in ethical consumption have shown an intention to behave ethically (e.g., Carrigan et al., 2004; Low and Davenport, 2007), authors (e.g., Auger and Devinney, 2007; Bray et al., 2011; Carrigan and Attalla, 2001; Carrigan et al., 2011; d'Astous and Legendre, 2009; Papaoikonomou et al., 2012) have also identified that there is a "significant difference between what consumers say about the importance of consumption-related ethical issues and their actual behaviour" (d'Astous and Legendre, 2009, p. 255). Cowe and Williams (2000) labelled this the 30:3 
phenomenon - in their study while $30 \%$ of UK consumers claimed to espouse ethical standards only $3 \%$ of purchases examined reflected those standards. This phenomenon has been labelled the attitudebehaviour gap (e.g., Boulstridge and Carrigan, 2000). Moser and Dilling (2007) in their exploration of changing responses to climate change demonstrated that providing more information did not necessarily lead to more action and that merely convincing people that a problem existed did not mean they would act on it. This implies that although people may make statements indicating an awareness of the arguments in favour using 'bags for life', they will not necessarily do so.

One explanation for the gap is that social desirability bias leads to inflated measures of consumers' intentions (Auger and Devinney, 2007; Carrigan and Attalla, 2001). Griskevicius et al. (2010) found that some people espoused "green" behaviour because they wished to appear superior to others and were thus status motivated. However, Carrington et al. (2010) argue that social desirability bias only partially explains the gap.

Bray et al. (2011) identify two theoretical approaches to understanding ethical decision making. The first is based on philosophical principles (Vitell et al., 2001) in which individuals make an ethical judgement based on rules/obligations and the consequences of taking action (Bray et al., 2011). This judgement informs both intention and behaviour. The second is based on the theory of reasoned action (Ajzen and Fishbein, 1980) and the theory of planned behaviour (Ajzen, 1991). Briefly, the theory of reasoned action argues that, in a given situation, behaviour is a direct function of intention, which in turn is a function of individual attitudes and subjective (social) norms (Ajzen and Fishbein, 1980). Ajzen's (1991) later included a further factor, perceived behavioural control: individual perceptions of societal pressure and individual control over the action. Armitage and Conner (2001) in a meta-analysis confirmed that the theory of planned behaviour was a good predictor of behavioural intentions and a reasonably good predictor of actual behaviour. However, even they concede that 80 per cent of the variance in people's behaviour was unexplained by factors in the theory. Later authors (e.g., Shaw et al., 2000) added additional factors to attitude such as ethical obligation and selfidentity; however the basic premise of a direct functional link remained. Bray et al. (2011) argued that 
theory of planned behaviour models failed to take into account the attitude-behaviour gap identified in empirical studies.

A number of more recent studies (e.g., Chatizidakis et al., 2007) have sought to explain the attitudebehaviour gap by considering not simply the attitude-intention gap, but by also considering the intention-behaviour gap. Specifically they have looked for causes and impediments that may prevent the translation of intention into action.

Chatzidakis et al. (2007) explored the justifications used by consumers to explain the discrepancy between their attitude and behaviour, categorizing them on the basis of Strutton et al's (1994) classification of rationalisations of norm-violating behaviour (known as neutralisation techniques). They identified four types: denial of responsibility (factors outside the consumer's control affect behaviour - cost, lack of information, inadequate availability or promotion); appeal to higher loyalties (financial constraints, convenience, inferiority of product); denial of injury or of benefit (changing behaviour would overall have little effect on the problem it was intended to solve or would make little difference); condemning the condemners (those advocating change are worse offenders themselves). D'Astous and Legendre (2009) in a study to develop a scale for appraising why consumers do not behave ethically used three types of justification: economic rationalism; economic development reality; and government dependency. An economic rationalism argument is one in which consumers think that to behave in a socially responsible manner is more costly to them than the benefits they receive; an economic development reality argument is one in which consumers think that to achieve economic growth and improve / maintain acceptable standards of living, ethical considerations have to be put aside (so costs outweigh benefits at a macro-level); a government dependency argument is one in which consumers take their lead from government cues, in other words if there is no government action to enforce socially responsible behaviour it is not viewed as having important consequences.

Both Chatzidakis et al. (2007) and d'Astous and Legendre (2009) argue that inclusion of the moderating effect of neutralisation techniques increases the explanatory power of the theory of planned behaviour (Ajzen, 1991). D'Astous and Legendre's (2009) framework treats (lack of) 
knowledge and perceived (in)effectiveness as antecedents to economic rationalization, economic development reality and government dependency justifications for not adopting socially responsible behaviour. They argue that these antecedents have a moderating effect on the adoption of such justifications such that they were found to be used less where knowledge about socially responsible behaviour and/or consumers' perceived effectiveness (belief their actions would make a difference) were greater. Whilst the studies above are concerned with cognitive justifications stemming from personally constructed rationalisations, other studies suggest more externally influenced barriers. Bray et al. (2011) used focus group data to identify factors impeding ethical behaviour despite ethical intentions (i.e., barriers to behaving ethically). They identified seven barriers: price sensitivity, personal experience, ethical obligation, lack of information, quality of goods, inertia, and cynicism (Bray et al., 2011). In our view, these factors represent a combination of external barriers (for example, price and quality) and neutralization techniques (for example, ethical obligation). The importance of barriers to ethical consumerism is also demonstrated by Moser and Dilling (2007, p.494) who argue that "for communication to facilitate a desired social change, it must accomplish two things: sufficiently elevate and maintain the motivation to change a practice or policy and at the same time contribute to lowering the barriers to doing so".

Both Chatizidakis et al. (2007) and d'Astous and Legendre (2009) suggest that an understanding of how consumers use neutralisation techniques to justify not changing behaviour can be used to formulate appropriate communication strategies which directly address those techniques themselves. Bray et al. (2011) suggest that by developing strategies to reduce the barriers between intention and action sustained behaviour change is easier to achieve. They argue that taking this intention-behaviour stage into account increases the predictive power of attitude-behaviour models.

In applying these theories to practice, WRAP's commissioned research into carrier bags usage and attitudes (Andrew Irving Associates, 2005) found that a 'bag for life' was re-used if and when respondents remember to do so. Therefore the embedding of ethical consumer behaviour (e.g. the uptake of 'bags for life') is not an isolated action; it is more complex. The literature tells us about 
justifications and neutralization techniques; what it does not tell us is what the role context plays in creating or overcoming barriers to this behaviour.

\section{The Importance of Context}

Carrington et al. (2010, p. 142) argue that since the majority of ethical consumer behaviour models are "built on a cognitive progression: (1) beliefs determine attitudes, (2) attitudes lead to intentions and (3) intentions inform behaviour", there is a tendency to treat intentions as determining behaviour. They highlight the importance of (1) the consumer's implementation plans (2) the actual behaviour control (whether the individual has the choice or ability to carry out the action) (3) the situational context of the individual. Implementation plans will reduce the moderation effects of behavioural control and environment/situational context.

Carrigan et al. (2011) argue that the role of social context in reducing the attitude-behaviour gap has been less explored. Consumers are "people engaged in socially embedded everyday practices" in which consumption is "deeply intertwined with social relations and norms" (Carrigan et al., 2011, p. 516). Achieving individual behavioural change requires changes not only in the habits of the individual but also in the social norms and relations surrounding the individual. This includes changing the environmental factors that would otherwise cue habitual behaviour and highlights the importance of collective actors in facilitating change (Carrigan et al., 2011).

Banerjee's (1992) model of herd behaviour discusses how people learn from and conform to behaviours of others. People tend to imitate the actions of those around them, those they trust and those who appear to have expertise. This suggests that embedding consumerism behaviours is a social process influenced by trusted persons close to the individual. Therefore friends and family have a significant influence.

Bikhchandani et al.'s (1998) informational cascade model suggest that this persuasive but fragile herd behaviour occurs because cascades are triggered by the choices of individuals which are in the public domain and are easily accessible to decision makers. According to Carrigan et al. (2011), influential individuals set normalising standards and play a role in establishing innovation, making changed 
behaviour socially acceptable (e.g. celebrity endorsements). Diffusion of innovation highlights the importance of opinion-leaders (Katz and Lazarsfeld, 1955; Rogers, 2003) in the adoption of ideas (Greenhalgh et al, 2004:602). Opinion leaders will have a positive impact on the implementation of new behaviour or behaviour changes. Bray et al (2011) highlight the importance of exposure in lowering barriers. The influence of popular media and governments may act as a catalyst in making the issues salient (d'Astous and Legendre, 2009). Haddock-Fraser (2010) suggested that the role of the media may be one (of many) components communicating corporate environmental performance as well as servicing the information needs of more direct stakeholders such as consumers, investors, employees and associated businesses. She found that "the Daily Mail campaign against carrier bag use by retailers...provides an example of how successful change to mainstream attitudes and behaviours can be led by the media" (p.32).

Carrigan et al. (2011) argue that organisations that are "interested in advancing sustainable lifestyles" (e.g., supermarkets in the 'bags for life' case) should "facilitate change through the implementation of targeted and effective" information provision at the point at which habits are susceptible to change combined with disruption of the environment in which the habitual behaviour occurs prior to that behaviour occurring. We emphasise the role of environmental context in giving appropriate cues and in disrupting habitual behaviour so as to instigate and reinforce behaviour change. We discuss the strategic contextual role of supermarkets in this process.

This has resonance with the work of Moser and Dilling (2007) who suggested that the saliency of the message needs to be supported by action and incentive at the point at which the individual has the opportunity to make intention, action. In this paper we argue that the role of the situational context is to turn knowing into doing.

Combining the literatures above, it is clear that the act of embedding behaviour is a processual one with a series of stages and factors that can impede the transformation of attitudes into behaviour. We therefore propose an exploratory model chronologising the process of embedding behaviour in terms of the persuasive statements used. At the early stage, we would expect most persuasive statements to 
focus on attitude for example, knowledge about the environment, understanding the environmental effects of use of plastic bags, and the social pressure of their peers and role models behaving in such a manner. At the next stage, the statements will focus on the attitude-intention gap, where these will centre on statements surrounding utilitarian benefits of using 'bags for life'. A follow-on stage focuses on the intention-behaviour gap where we will have greater understanding of the importance of 'bags for life'; however statements will focus on how to turn that into an action. At this point, we will perceive a higher percentage of uptake, but we might then expect the focus of statements to switch back to attitude to address later adopters.

This proposed model extends the current literature in understanding the attitude-behaviour gap in an empirical setting. It identifies stages that these gaps occur so that both institutional and individual interventions can be appropriately focused. This is a significant shift from current literature. Current literature has identified the various potential causes of the attitude-behavioural gap. What this paper proposes to do is to go one step further and identify which interventions might work at various embedding stages.

\section{Present study}

In this exploratory study, we begin to unpack some of the contextual barriers which may influence ethical consumerism. We use a case study analysis to try and understand why this instance of ethical behaviour change has stalled at $5 \%$ of total bags issued and the use of 'bags for life' has not become sustained, embedded behaviour such that a much larger proportion of total bags issued are 'bags for life'. We do this by examining the attitudes which influenced people to use 'bags for life', and how people persuade others to take up 'bags for life'. Therefore, research question one is 'What are the consumers' attitudes towards the importance of the use of bags for life?'.

Due to the effect of social desirability on measures of consumers' intentions (Auger and Devinney, 2007; Carrigan and Attalla, 2001) it was important that we were able to understand the respondents' underlying motivations. By analysing the persuasive arguments we were able to see the transference 
of these motivations in encouraging their friends to be ethical. Therefore, research question two is 'How do people translate attitude into behaviour?'.

In exploring potential barriers in the context of the use of 'bags for life', we identified from literature three aspects of context that may be significant. These are immediate social networks (i.e. friends and family), wider influential parties (i.e. media and government) and invested organisations (i.e. supermarkets). We try to identify any potential role that they may play, from the perspective of the consumers. Research question three is "What aspects of context (media/government, friends and family, supermarkets) are important in changing behaviour towards the use of 'bags for life'?'

\section{$\underline{\text { Data collection }}$}

We use the example of usage of 'bags for life' in the UK as a longitudinal case study to examine the attitude-behavioural gap in ethical consumption. This represents a good example where despite a number of interventions, ethical behaviour, as expressed in the use of 'bags for life' has not become the more dominant, widespread behaviour (WRAP 2012). While the number of 'bags for life' issued has increased, 'bags for life' as a proportion of total bags issued has remained static at $5 \%$ for some years. By taking a holistic approach to studying ethical consumerism we can gain insight to the influencing roles and interconnectedness of various aspects of complex ethical behaviour adoption.

In order to achieve this holistic perspective on the case study we collected data from a variety of sources over a six year period (2006-2012). This included the analysis of over 120 media and press coverage articles covering various 'bags for life' adoption initiatives; 17 publically available commercial or government documents detailing intervention activities and performance measures; ad hoc observation of ethical consumerism forums and social media feeds (especially targeting 'bags for life' threads and ethical consumerism groups), recorded as case notes throughout the period; and the administration of an online questionnaire focusing on the translation of attitudes and behaviours (a full breakdown of our data sources is included in the reviewers' supplementary materials provided). In using these methods we aimed to develop work in this area by observing the changes in attitudes, 
intentions and behaviours in a real-time empirical study to understand how behaviour becomes sustained and embedded.

Online questionnaire: The data were collected via an on-line questionnaire. The questionnaire was piloted and tested amongst university undergraduates. This formed part of a larger survey investigating ethical consumerism. On-line collection was used to reach a variety of respondents, not just those who shopped at supermarkets. The questionnaire link was posted on several university websites, professional networks and discussion forums, and subsequently snowball sampling was utilised. Although Biernacki and Waldorf (1981) argued that snowball sampling can be biased because it is not random and selects individuals on the basis of social networks, Noy (2008) argues that it is an effective method of deriving knowledge that is dynamic and network-based. Given the importance of networks outlined above, we take the latter view. Effort was made to ensure the format, language and style used in the questionnaire was clear, understandable, aesthetically pleasing and relevant to potential respondents to minimise non-response and the risk of respondents becoming bored or antagonised which could affect the reliability of the questionnaire responses. Answers are retrospective, require participants to remember and accurately recall all the details and only give a snapshot of opinion at a point in time, rather than the development of underlying processes over time.

The online questionnaire consisted of a combination of open and closed questions. The first section of the questionnaire asked respondents about their shopping behaviours, e.g. "how many times a week do you go food shopping at the supermarket?", "when going food shopping which of the following are you most likely to use? (free plastic bags provided at the checkout, plastic bags which you have to pay for at the checkout, I bring my own bags/use a 'bag for life', I try not to use any bags, other) and whether they owned a 'bag for life'. The options for this question, and those below, were derived from the pilot study where open ended questions were used and responses coded to create these categories.

For those respondents who indicated that they did own a 'bag for life' they were asked "how long have you owned a 'bag for life'?" (options ranged from 'less than a month' to 'over 5 years') and 
"where did you first hear about 'bags for life'?" (through the media (TV, radio, newspapers), through the supermarkets (e.g. at the checkout or through a promotion), from friends and family, other). Respondents were then asked to score a variety of statements based on how much it had encouraged them to start using 'bags for life' on a 5 point Likert scale ranging from 'not important at all' to 'very important'. The statements were: "supermarkets encouraged me to start using 'bags for life"; "family and friends began using 'bags for life"”; "there was pressure from the media and government to "do your bit"; "plastic bags can cause damage to the environment"; "the quality of 'bags for life' bags increased"; they were given away free/on promotion at the supermarket" and "the supermarket started charging for normal plastic bags".

Finally, an open question was posed which asked "If a friend asked you whether they should start using 'bags for life' and why, what would you tell them?". A key element of embedding behaviour change such that it becomes sustained at a collective level is the diffusion of the message for behaviour change throughout social networks, eventually reaching a point at which the new behaviour becomes the social norm rather than the exception/ innovation. The aim of this open question was to capture this element of embeddedness as opposed to the individual's own given reasons for use. By asking them to convey the message to a friend we are asking them to highlight the factors which they think could be the most persuasive thus revealing their underlying motivations for using 'bags for life'.

Given the identification in the literature of possible social desirability bias in self-reported behaviour (Auger and Devinney, 2007; Carrigan et al., 2010; Griskevicius et al, 2010) reporting , a 33-item social desirability scale (Crowne and Marlowe, 1960) was also used to see if the respondents were the type of individuals who would like to portray themselves positively. That is to say, they would attempt to depict themselves as similar to the norms and standards of their society and community. This scale has been tested over the last five decades and has been found to be robust (Loo and Loewen, 2004). An example question would be: "I always try to practise what I preach".

\section{Data Analysis:}


Quantitative data from the online questionnaire were exported to a statistical analysis software package (SPSS) where descriptive, correlation and regression analyses were performed. Qualitative data from the questionnaire were analysed using content analysis (Krippendorff, 1980). The authors independently noted dominant themes in the data and coded a representative sample of the responses. Inter-researcher differences were resolved through discussion and reference back to the responses as suggested by Miles and Huberman (1994). The full data set was then coded by one author. Media and documentary evidence were organised chronologically and reviewed by the research team for themes which supported the emerging aspects of context and to add additional explanation to our findings. The roles of various actors (retailers, government, and the public) were analysed and integrated to our overall case study analysis (Greenwood and Hinings, 2006).

\section{Findings:}

\section{Descriptive Statistics}

The sample comprised 316 respondents. This sample represents approximately equal proportions of male $(49 \%)$ and female $(51 \%)$ respondents, a variety of household income ranges (under $£ 10,000=$ $4.3 \% ; £ 10-20,000=7.3 \% ; £ 20-30,000=9 \% ; £ 30-40,000=15.8 \% ; £ 40-50,000=10.3 \% ; £ 50-60,000$ $=13.7 \% ; £ 60-70,000=11.5 \% ;$ and $£ 70,000+=28.2 \%)$ and ethnic groups $($ White $=86.3 \% ;$ Mixed $=$ $2.9 \%$; Indian $=1.3 \%$; Black African $=1.3 \% ;$ Black Caribbean $=0 \% ;$ Black other $=0 \%$; Chinese $=$ $5 \%$; Other $=3.3 \%$ ) were included in the sample with white, high earners making up a large group within the sample. To check for bias we checked these demographic variables against the 'bag for life' attitudes measures (used below) for inference that may indicate that they had influenced our findings. No difference in mean scores was found for either gender or ethnic groups for 'bag for life' ownership or the importance of any of our variable in encouraging ownership of 'bags for life'. On this basis we can be confident that any sample misrepresentation on the basis of ethnicity variable did not impact on our findings in this paper. There were however some correlations between household income and the importance of family and friend $(\mathrm{r}=-.180, \mathrm{p}=.016)$, media and government $(\mathrm{r}=.196$, $\mathrm{p}=.009)$, quality of bags $(-.164, \mathrm{p}=.030)$, and charging for single-use bags $(-.150, \mathrm{p}=.047)$ with higher household income groups rating these as lower importance in their decision to start using a 'bag for 
life'. Ownership of a 'bag for life' itself $(\mathrm{r}=-.061, \mathrm{p}=.361)$, the importance of supermarket encouragement $(\mathrm{r}=-.143, \mathrm{p}=.056)$ and the importance of environmental impact $(\mathrm{r}=-.052, \mathrm{p}=.491)$ were not significantly correlated with income. This represents an interesting finding on the effectiveness of various uptake interventions which we discuss later. An age range of 50 years (18-68 years, Mean=39 years, $\mathrm{SD}=11.632$ ) was included in the sample. A majority of respondents went shopping once or twice a week (88.6\%), and more than half were regular 'bag for life' users, although $31.6 \%$ admitted using free single-use bags regularly. Almost $80 \%$ of respondents owned a 'bag for life'. Unless otherwise stated, only respondents who claimed to own a 'bag for life' were asked the remaining questions regarding their use of these bags.

\section{Attitudes towards 'Bags for Life':}

Research question 1 asked what consumers' attitudes were towards the importance of using 'bags for life'. Respondents who used 'bags for life' were asked to what extent they considered various influences were important factors in their decision to start using them (items were rated on a 5 point scale with 5 being extremely important and 1 being not important at all). Table 1 shows the mean scores for each of the factors. The 'environmental impact' was the highest influencing factor on starting to use 'bags for life' $(\mathrm{M}=4.09, \mathrm{SD}=1.172)$. This would suggest that the main attitude which has led to behaviour is the 'environmental' message.

INSERT TABLE 1 HERE (Table 1: Important influences in uptake of 'Bags for Life')

However, we tested the impact of social desirability on each of these influences. Analysis of the responses to important attitudes revealed that a high score on the influence of environmental impact was positively correlated with high social desirability scores: $\mathrm{r}(182)=.209, \mathrm{p}=.005$. We found that in fact social desirability significantly predicted environmental attitudes: $\mathrm{R}^{2}=.044, \mathrm{~F}(1,180)=8.261$, $\mathrm{p}=.005$, which suggests that attributing environmental impact as a reason for using 'bags for life' is a socially desirable answer to give. The importance of the increased quality and desirability of 'bags for life' was also found to be significantly predicted by social desirability $\mathrm{r}(180)=.171, \mathrm{p}=.022, \mathrm{R}^{2}=$ $.029, \mathrm{~F}(1,178)=5.352, \mathrm{p}=.022$, which suggests additional quality is also a socially desirable response, possibly because it also effects environmental impact. However, we did not find that social 
desirability was a significant predictor of owning a 'bag for life' $\mathrm{R}^{2}=.010, \mathrm{~F}(1,225)=2.356, \beta=.102$, $\mathrm{t}(224)=1.535, \mathrm{p}=.126$. The link between social desirability and environmental influences therefore suggest that other attitudes and opinions in the wider context play a role in the decision to use "bags for life'.

\section{Translating attitudes to behaviour:}

Of the 316 surveys completed 163 answered the question "how would you persuade your friends...". Of these 141 were coded based on the following themes: environment (this included responses which talked about reducing waste and conserving or making better use of resources); personal utility (this included responses such as reducing clutter in the home or 'bags for life' being stronger than singleuse bags); personal economics ('bags for life' will reduce costs, save money); social (everyone is doing it, it makes you look good); advice on remembering to use them (keep some in your car; in your handbag). The themes were informed by the literature exploring the reasons for an attitude-behaviour gap in the adoption of socially responsible behaviour. The remaining 24 non-blank responses either simply said "yes" (9 responses), gave a command "do it", "change now" (9 responses) or queried current behaviour action "why are [you] still using one-use carrier bags?" (1 response); 3 responses were uncategorisable and mentioned such things as vulnerability to shoplifting and doing it for one's own reasons (see table 2). Of the 141 coded responses, 62 gave persuasive statements that combined two or more themes (46 gave two themes; 14 gave three and 2 gave four themes). Where three themes were combined in a persuasive statement (14 in all) 10 combined environment and utility with one other theme, with five responses placing environment first and five placing utility first. A further three responses combined environment and economics with either social or advice for remembering to use 'bags for life'; of these two placed economics first.

\section{INSERT TABLE 2 ABOUT HERE (Table 2: Primary statement frequency)}

The overwhelming number of responses in which environment is the sole or primary theme of the statement suggests that respondents are focusing on changing the attitude of their friends, the first stage in the chronology of embeddedness. However, that utility is the second highest theme used in 
statements and is the most often used theme when environment is combined with another theme in a statement suggests that some respondents are also thinking about how to address the attitude-intention gap. The combined statement using both environment and utility is interesting because it both addresses attitude but also anticipates that friends might adopt neutralisation techniques.

\section{Important Aspects of Context:}

We have already mentioned the importance of putting a situational context when trying to understand the gaps between attitudes, behaviour and intention (Carrigan et al, 2011; Moser and Dilling, 2007). Within this exploratory study, we have taken situational context to include the role of institutions such as supermarkets, media and government, and the role of individuals such as friends and family.

\section{Institutional role - Media, Government and Supermarkets}

The data shows that the majority of respondents began using 'bags for life' 3-4 years ago. This corresponds with the 2008 voluntary agreement between BRC, leading supermarkets and the UK governments to reduce single-use carrier bag. While there had been announcements by individual supermarket chains before this, this marked a more widespread and concerted effort by retailers to effect change in consumer behaviour. There are self-reported initiatives of supermarkets to promote 'bags for life' and reduce the visibility of free single-use bags at checkouts during the voluntary agreement. Sainsbury's, for example, promoted free 'bags for life' in April 2007, followed by Marks \& Spencer in April 2008 and Morrison's in May 2008. In May 2008 Marks and Spencer also began to charge (5p) for single-use plastic bags. These giveaways were followed in quick succession by the

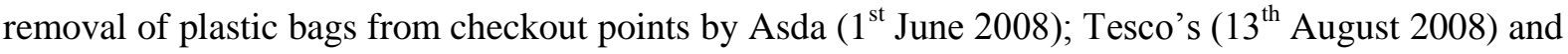
Sainsbury's ( $1^{\text {st }}$ October 2008) and The Co-operative group and its sister Co-operative Societies (various dates 2008).

This increase of activity by supermarkets to support the use of 'bags for life' instead of single-use bags correlates with the time which most of our respondents suggested they began using 'bags for life' (See Figures $1 \& 2$ ). In addition, when asked where they heard about 'bags for life' the most popular response was, "from the supermarkets" (67\% of respondents). This suggests that the active 
involvement of supermarkets in the reduction of single-use bags was a key factor in initiating a change in 'bags for life' usage.

INSERT FIGURE 2 ABOUT HERE (Figure 2: 'Bags for Life' Timeline ( $\mathrm{t}=0$, Spring 2010))

As mentioned above, the citation of environmental factors in the uptake of 'bags for life' was highly correlated with social desirability suggesting that the respondents perceive this to be a reason why they should use 'bags for life', but it also suggests that it may not have been the actual reason for the initial uptake.

If the environmental factors and the desirability/utility of the bag are removed from the list of factors, the next most important factors given for the uptake of 'bags for life' were supermarket related. These were: the encouragement of the supermarket $(\mathrm{M}=2.98, \mathrm{SD}=1.278)$, the supermarkets charging for plastic bags $(\mathrm{M}=2.87, \mathrm{SD}=1.412)$, and supermarkets offering free promotional 'bags for life' $(\mathrm{M}=2.68, \mathrm{SD}=1.376)$, none of which were correlated with social desirability.

It is clear that the media and major supermarkets have had significant roles to play in campaigning towards a reduction in use of single-use bags. Indeed, some of the ways supermarkets have helped include creating an aide memoire (Sainsbury's in April 2008 created 'take an old bag shopping' fridge magnets), charging for single-use bags (generally 5-10 pence per bag) and offering green loyalty points (Sainsbury's and Tesco).

However, once the voluntary agreement ended in 2009 a slow but steady increase in use of single-use bags has been observed. This contrasted sharply with Ireland's reported tax on single-use bags being a dramatic success. In September 2011, the Welsh government imposed a tax on single-use bags, and 10 months later in July 2012, Welsh supermarkets reported reductions of up to $96 \%$ in the use of single-use bags since the tax was introduced. In October 2012, it was reported that this tax alone raised $£ 800,000$.

This provides strong support for institutions such as the government, media and supermarkets, to play an important role in creating a supportive context for which behaviour change to occur. 


\section{Individual role - Friends and Family:}

Friends and family also exert an influence on people's decisions. We were interested in exploring in more detail the themes adopted by our respondents in statements about what they would say to friends and family as part of the process of persuading them to use 'bags for life'. As reported above we compared the relative frequency of the different themes used in the statements and ranked them from high to low to summarise our observations. Representative data of the different themes in the statements are given in Table 2. We can see that environment ranks the highest in terms of theme adopted in statements used to persuade their friends and family. This is followed by personal utility and then advice on remembering. Understanding the persuasive statements will help us draw on some of the ways in which individuals can go about encouraging and influencing others to reuse 'bags for life'.

\section{$\underline{\text { Discussion }}$}

In this study, we drew on the attitude-behaviour gap literature in ethical consumerism and applied it to the example of using of 'bags for life' to explore the relationship between the recognition of the need for changed behaviour, taking action and embedding the action so that it becomes routinized and sustained. We make a contribution to research on embedding ethical behaviours by demonstrating how context might influence the adoption of new behaviours by turning the knowing into doing.

By combining our review of the relevant literature and our empirical study we expand on the exploratory model proposed above which outlines the process of embedding behaviour. Our model proposes that attitudes about 'bags for life' were formed through environmental arguments and social pressures to 'do your bit'. Individual level interventions are important, such as, high profile opinion leaders or the individual's closer social network (i.e. friends and family) in turning these attitudes into intentions. They do this by emphasising the personal economic and utility benefits of the behaviour (e.g. "your house will be less cluttered") to encourage 'bag for life' intentions. There is however, an important role for other collective actors to influence the process and turn intentions into behaviour by reducing the 'I forgot' scenario by reinforcing new behaviour, punishing old behaviour or removing barriers to behaviour (for example, supermarket 'remembering' promotions, charging for single-use 
bags, or giving reward points). Our case study demonstrated that these activities must continue until behaviour becomes embedded.

An interesting finding emerged which suggested that individuals with a higher household income perceived the influence of the media and family and friends to be less important in influencing their decision to start using 'bags for life'. In addition increasing quality of bags and the introduction of having to pay for single-use bags were also less influential on those with higher household incomes. This would suggest that in future campaigns to increase usage of 'bags for life' particular initiatives may be more effective than others, depending on the target group. For example, for a supermarket whose target demographic tended to be higher income households an initiative focused on charging for single-use bags would be less likely to be effective. The importance of encouragement from supermarkets and environmental impact did not correlate by household income. This is worthy of further study in future research.

Our data found that $80 \%$ of our respondents claimed to own at least one 'bag for life', and there was general positivity towards the use of 'bags for life'. However, the proportion of single use bags has not dropped and the proportion of 'bags for life' has not increased (WRAP 2012). This suggests that the use of 'bags for life' has yet to become widely embedded. Evidence of sustained, widely embedded behaviour will emerge if the proportion of single-use bags issued decreases significantly and that of 'bags for life' significantly increases.

So, what will encourage long-term behavioural change? Our data suggest that in the vast majority of our sample, the environmental message has been received and people are very aware of the environmental impact of the use of single-use bags. In this sense, the 'attitude-intention gap' has been narrowed and our sample seems to demonstrate that the message of using 'bags for life' is getting through; whether through environmental messages or the social messages (it's cool to be seen using 'bags for life').

However, what is not so clear is the conversion of the intention to behaviour. There seems still to be a significant 'intention-behaviour' gap. One reason we can identify from respondents' statements, which is supported by the 2005 report to WRAP (Andrew Irving Associates, 2005), is that they forget 
to bring their 'bags for life' when going shopping. A few respondents indirectly commented on convenience issues with statements such as "I prefer the nylon bags which fold into their own little bags, as they're a lot smaller than the normal 'bags for life' from supermarkets ... I have three of them in my handbag," and "tend ... towards having planned shopping activity,". Although these may be interpreted as the adoption of neutralisation techniques they also point to further actions that supermarkets and high street stores could take regarding design, such as the handbag or pocket-sized 'bags for life' that are now available. Evidence has demonstrated that when the major supermarkets took positive steps to encourage actual behaviour change at the point of purchase (or action), the use of 'bags for life' increased significantly. This suggests that the influence that institutions provide in the situational context can play an important role in converting the already positive attitude into the actual behaviour to use 'bags for life'. Other reasons identified by the 2005 report included the continued use of single-use bags for non-food and high street shopping. This was outside the scope of the survey in this paper but points to suitability/availability of bag-type in a wider context and perhaps indicates why single-use bags are unlikely to be eradicated entirely. Again, this is worthy of further research.

According to Sainsbury's environmental manager, "by working with our customers to achieve this reduction we believe we are bringing about long-term behavioural change" (WRAP, 2010). The CoOperative Bank agrees with this and in their ethical consumerism report (2009:2), writes that although the "idea of ethical purchasing is now well established amongst many consumers, there is still a long way to go if we are all going to adopt the low carbon lifestyle.... and this will need a new contract between business, government and the consumer." Since the 'voluntary agreement' ended, it has left a vacuum in terms of institutional involvement in bringing this agenda forward. Institutions may be working in individual capacities in encouraging use of 'bags for life', however by taking a collective institutional action, the momentum can be sustained.

\section{Conclusions}


This paper makes several important contributions to the existing literature on attitudes and intentions towards ethical behaviour. The first contribution is that by taking a holistic view of institutionsindividual interactions, we have looked at the chronology of how attitudes contribute to intention formation which mediates behaviour change. This paper argues that both institutions and individuals have an active amplification role to play in contributing to the eventual embedding of this behaviour. Other literature in this field have either focused on attitudes-intention, or the intention-behaviour gaps. Our findings demonstrate that individuals play a significant role in encouraging attitudinal change, and institutions are necessary for closing the intention-behaviour gap. These need to go hand in hand in order to effect a sustained change in behaviour. The second contribution is methodological. Rather than asking people to identify the barriers towards the use of 'bags for life', we have asked them to articulate how they would personally persuade their friends and family to adopt their use. This is important because it identifies the attitude-behaviour gap that persists in their social settings. This will help in future campaign planning. By understanding the extent of attitudinal change and the stage reached in embedding behaviour change, future campaign planning can target the appropriate stage which these attitudes have reached with the appropriate level of intervention (individual or institutional). 


\section{References:}

Ajzen, I. (1991). The theory of planned behaviour. Organizational Behaviour and Human Decision Processes, 50, 179-211.

Ajzen, I. and Fishbein, M. (1980). Understanding Attitudes and Predicting Social Behavior. PrenticeHall, Englewood Cliffs, NJ.

Andrew Irving Associates. (2005). Carrier bag usage and attitudes: Benchmark and target market survey. http://www.wrap.org.uk/sites/files/wrap/CarrierBagUsage.pdf

Armitage, C. J. and Conner, M. (2001). Efficacy of the theory of planned behaviour: A meta-analytic review. British Journal of Social Psychology 40, 471-499.

Auger, P. and Devinney, T. M. (2007). Do what consumers say matter? The misalignment of preferences with unconstrained ethical intentions. Journal of Business Ethics 76, 361-383.

Banerjee, A. V. (1992). A simple model of herd behaviour. The Quarterly Journal of Economics 107, $797-817$.

BBC News (2008). Plastic bag bans around the world. $28^{\text {th }}$ February, http://news.bbc.co.uk/go/pr/fr//1/hi/world/7268960.stm Accessed 3 October 2012.

Biernacki, P. and Waldorf, D. (1981). Snowball sampling: Problems and techniques of chain referral sampling. Sociological Methods and Research 10, 141-163.

Bikhchandani, S., Hirshleifer, D. and Welch, I. (1998). Learning from the behavior of others: Conformity, fads and informational cascades. The Journal of Economic Perspectives 12, 151-170.

Boulstridge, E. and Carrigan, M. (2000). Do consumers really care about corporate responsibility? Highlighting the attitude-behaviour gap. Journal of Communication Management 4(4), 355-368.

Bray, J., Johns, N. and Kilburn, D. (2011). An exploratory study into the factors impeding ethical consumption. Journal of Business Ethics 98(4), 597-608. 
British Retail Consortium. (2010). http://www.brc.org.uk/ Accessed 17 June 2010.

Carrigan, M., and Attalla, A. (2001). The myth of the ethical consumer - do ethics matter in purchase behaviour? Journal of Consumer Marketing 18(7), 560-577.

Carrigan, M., Moraes, C. and Leek, S. (2011). Fostering responsible communities: A community social marketing approach to sustainable living. Journal of Business Ethics 100, 515-534.

Carrigan, M., Szmigin, I. and Wright, J. (2004). Shopping for a better world? An interpretive study of the potential for ethical consumption within the older market. Journal of Consumer Marketing 21 (6), 401-417.

Carrington, M. J., Neville, B. A. and Whitwell, G. J. (2010). Why ethical consumers don't walk their talk: Towards a framework for understanding the gap between the ethical purchase intentions and actual buying behaviour of ethically minded consumers. Journal of Business Ethics 97, 139-158.

Chatzidakis A., Hibbert, S. and Smith A. P. (2007). Why people don't take their concerns about fair trade to the supermarket: The role of neutralisation. Journal of Business Ethics 74, 89-100.

Cooper-Martin, E. and Holbrook, M. E. (1993). Ethical consumption experiences and ethical space. Advances in Consumer Research 20 (1), 113-118.

Cowe, R. and Williams, S. (2000). Who are the ethical consumers? The Cooperative Bank, London.

Crowne, D. P., and Marlowe, D. (1960). A new scale of social desirability independent of psychopathology. Journal of Consulting Psychology, 24, 349-354.

d'Astous, A. and Legendre, A. (2009). Understanding Consumers' Ethical Justifications: A scale for Appraising Consumers' Reasons for Not Behaving Ethically. Journal of Business Ethics 87, 255-268.

Greenhalgh, T., Robert, G., Macfarlane, F., Bate, P. and Jyriakidou, O. (2004). Diffusion of innovations in service organizations: Systematic review and recommendations. The Milbank Quarterly $82(4), 581-629$. 
Greenwood, R., and Hinings, C.R. (2006). Radical organizational change. In S.R. Clegg, C. Hardy, T.B. Lawrence, \& W.R. Nord (Eds.), The Sage handbook of organization studies (2nd Ed): 814-842. Sage, London.

Griskevicius, V., Tybur, J. M., and Van den Bergh, B. (2010). Going green to be seen: Status, reputation, and conspicuous conservation. Journal of Personality and Social Psychology 98, 392-404.

Haddock-Fraser, J. (2010). The link between corporate brands and eco-management: The role of the news media. Kent Business School Working Paper Series no. 224.

Hayabuchi, Y., Enomoto, Y., Yamasue, E., Okumura, H. and Ishihara, K., N, (2005). The role of environmental education and social system on the plastic bag problem. In: Proceedings of 3rd Conference on the Public Sector Ljubljana, Slovenia

James K, and Grant T. (2003). LCA of degradable plastic bags www.cfd.rmit.edu.au/content/download/232/1787/.../James_and_grant.pdf

Katz, E. and Lazarsfeld, P. F. (1955). Personal Influence: The part played by people in the flow of mass communications. New York, NY: The Free Press.

Krippendorff, K. (1980). Content Analysis: An Introduction to its Methodology. Beverly Hills, CA: Sage.

Lewis, H., Verghese, K. and Fitzpatrick, L. (2010). Evaluating the sustainability impacts of packaging: the plastic carry bag dilemma. Packaging Technology and Science 23, 145-160.

Loo, R. and Loewen, P. (2004). Confirmatory factor analyses of scores from full and short versions of the Marlowe-Crowne Social Desirability Scale. Journal of Applied Social Psychology 34, 2343-2352.

Low, W. and Davenport, E. (2007). To boldly go . . exploring ethical spaces to re-politicise ethical consumption and fair trade. Journal of Consumer Behaviour 6, 336-348. 
May, C. and Finch, T. (2009). Implementing, embedding and integrating practices: An outline of normalization process theory. Sociology 43 (3), 535-554.

Miles, M. and Huberman, M. A. (1994). Qualitative Data Analysis (2nd ed.). London: Sage.

Moser. S. and Dilling, L. (2007). Towards the social tipping point: Creating a climate for change. In

S. Moser \& L. Dilling (Eds.). Creating a Climate for Change: Communicating Climate Change and Facilitating Social Change. (pp. 491-516) Cambridge: Cambridge University Press.

Newholm, T. and Shaw, D. (2007). Studying the ethical consumer: A review of research. Journal of Consumer Behaviour 6, 253-270.

Noy, C. (2008). Sampling knowledge: The hermeneutics of snowball sampling in qualitative research. International Journal of Social Research Methodology 11, 327-344.

Papaoikonomou, E., Valverde, M. and Ryan, G. (2012).Articulating the meaning of collective experiences of ethical consumption. Journal of Business Ethics 110, 15-32.

Roach, J. (2008). Plastic bag ban gaining momentum around the world. National Georgraphic News $4^{\text {th }}$ April, .

Rogers, E.M. (2003). Diffusion of Innovations. New York, NY: Norton.

Sharp, A., Høj, S. and Wheeler, M. (2010). Proscription and its impact on anti-consumption behaviour and attitudes: the case of plastic bags. Journal of Consumer Behaviour 9 (6), 470-484.

Shaw, D., Shiu, E. and Clarke I. (2000). The contribution of ethical obligation and self-identity to the theory of planned behaviour: An exploration of ethical consumers. Journal of Marketing Management 16(8), 879-894.

Strutton, D., Vitell, S.J., and Pelton, L.E. (1994). How consumers may justify inappropriate behaviour in market settings: An application on the techniques of neutralization. Journal of Business Research, 30, 253-260. 
The Co-operative Bank (2009). Ten Years of Ethical Consumerism: 1999-2008. http://www.cooperativebank.co.uk/corp/pdf/Ethical_Consumerism_Report.pdf Accessed 13 July 2011.

The Co-operative Group. (2012). Ethical Consumerism Report 2011. http://www.cooperative.coop/PageFiles/416561607/Ethical-Consumerism-Report-2011.pdf Accessed 3 October $\underline{2012 .}$

Vitell, S. J. Singhapakdi, A. and Thomas, J. (2001). Consumer ethics: An application an empirical testing of the Hunt-Vitell theory of ethics. Journal of Consumer Marketing 18 (2), 153-178.

WRAP. (2010). Waste and Resources Action Promme. http://www.wrap.org.uk/retail/carrier bags/carrier bags 50.html Accessed 26th August 2010.

WRAP. (2012). New figures on carrier bags use released by WRAP. http://www.wrap.org.uk/content/new-figures-carrier-bages-use-released-wrap Accessed 3 October 2012. 
Figure 1: Number of bags issued compared with proportion of bags issued

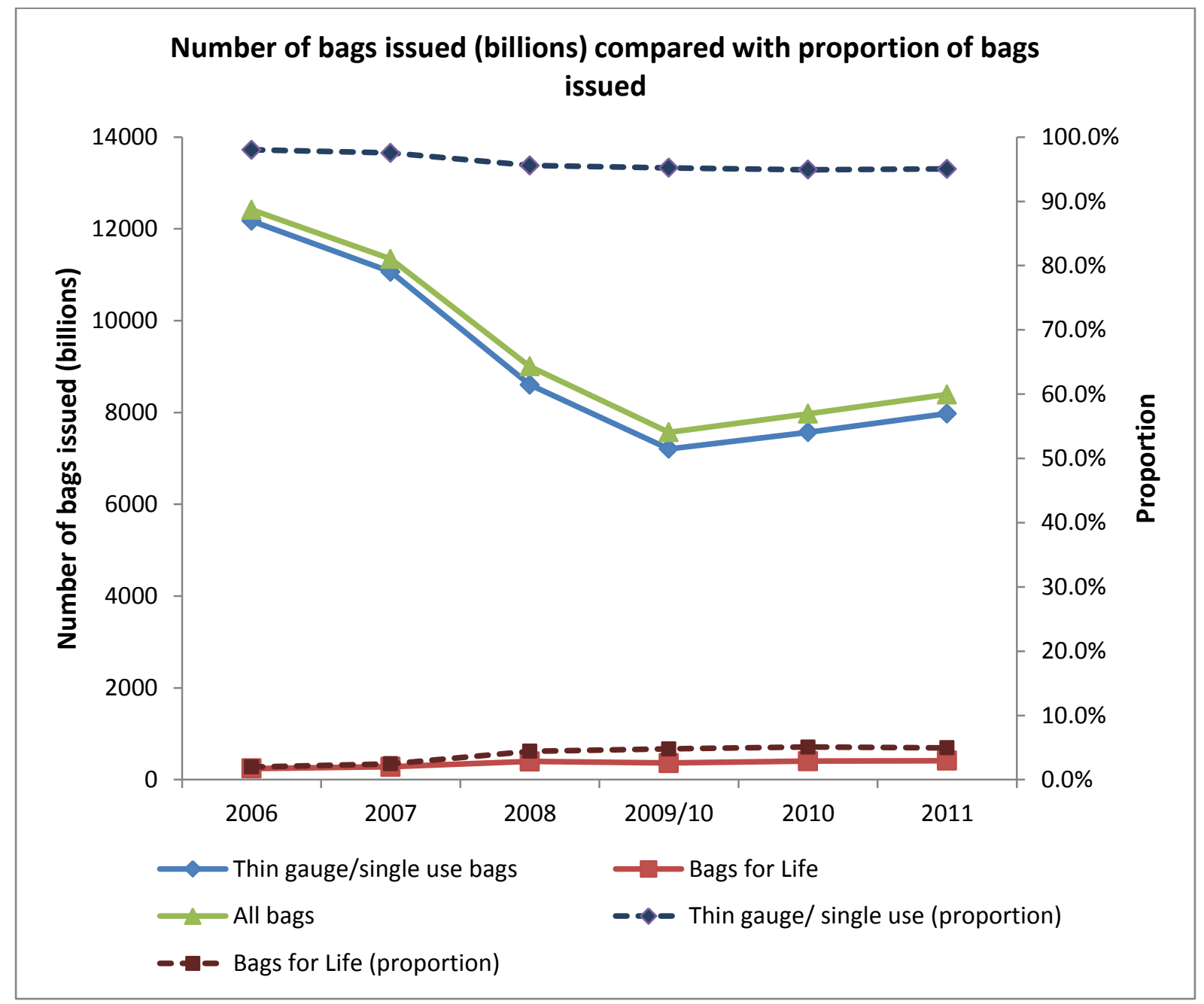


Figure 2: 'Bags for Life' Timeline ( $t=0$, Spring 2010)

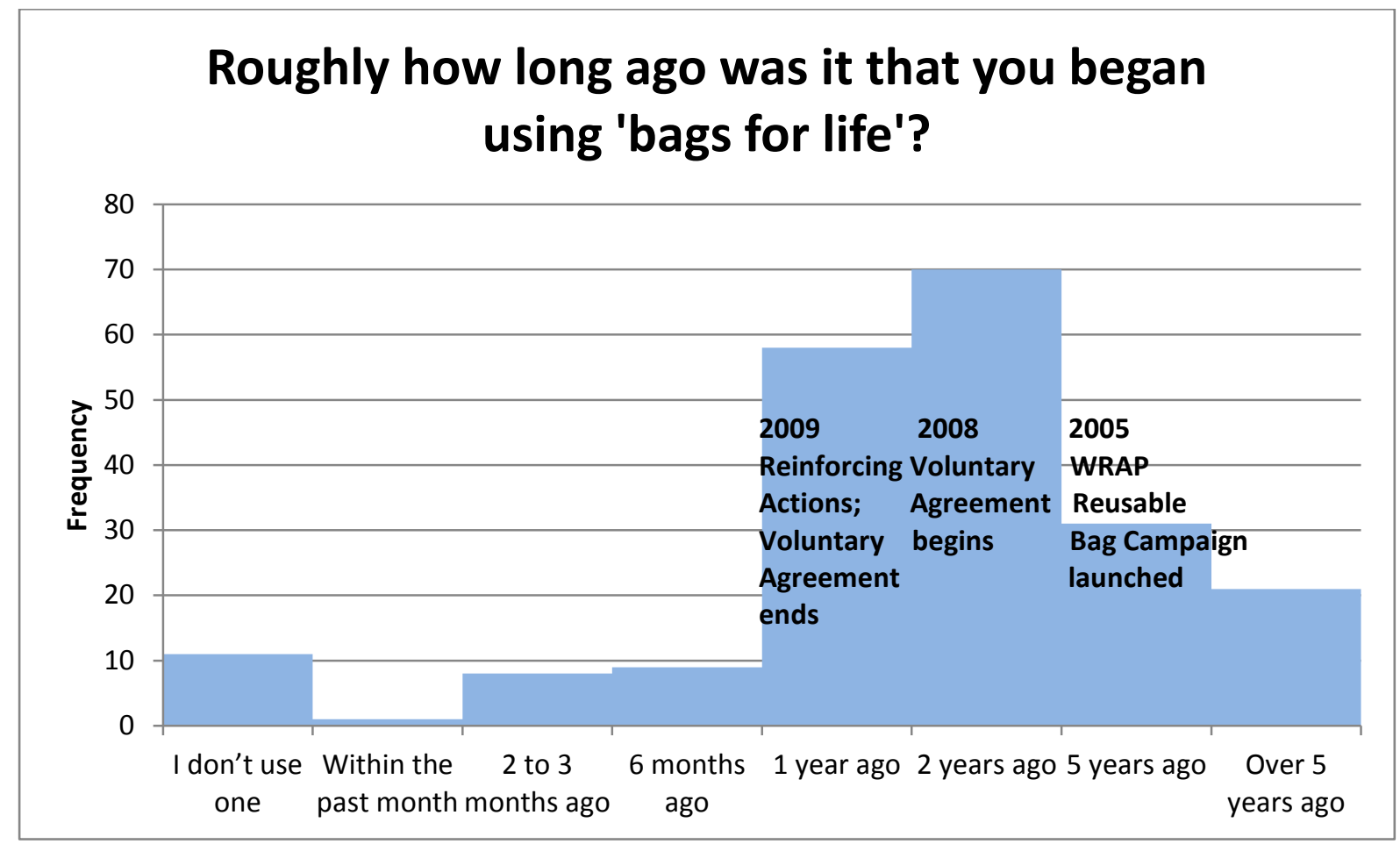

